\title{
Extended Hypofractionated Cancer Radiation Therapy Against Aged and Non-aged Breast Carcinomas Patients
}

\author{
Rawshan Ara Khatun, Julekha Khatun and Kutub Uddin Ahamed
}

\section{ABSTRACT}

We led an investigation to decide if hypo fractionated 35-days timetable of entire breast radiation is pretty much as viable. Women who bearing obtrusive breast carcinoma had gone through breast monitoring a medical procedure and resection edges were clean and partially lymph hubs were negatively approached with haphazardly relegated to get entire bosom illumination either at a control portion of $50 \mathrm{~Gy}$ in 15 divisions over a time of 45 days or at a portion of $45.5 \mathrm{~Gy}$ in $\mathbf{1 2}$ parts over a time of 22 days (the hypo fractionated-radiation bunch). The repetition at 36 months were 7.2\% among the 301 ladies allocated to standard illumination as contrasted and $7.6 \%$ among the 312 ladies allocated to the hypo fractionated routine. At 36 months, $69.5 \%$ of ladies in the benchmark group as contrasted and $\mathbf{7 1 . 2 \%}$ of the ladies in the hypo fractionatedradiation bunch had a decent or astounding restorative result. 3 years after therapy, sped up, hypo fractionated entire breast illumination was not sub-par compared to standard radiation therapy in ladies who had gone through breast preserving a medical procedure for obtrusive bosom malignant growth with clear careful edges what's more, negative axillary hubs. The ideal fractionation plan for entire bosom light after bosom rationing medical procedure is obscure.

Keywords: Hypofractionated-radiation, breast cancer, conserving surgery, mastectomy, Clinical Oncology.

Published Online: July 11, 2021

ISSN: $2736-5476$

DOI: 10.24018/ejclinicmed.2021.2.3.59

Rawshan Ara Khatun *

Department of Radiotherapy, Rajshahi Medical College Hospital, Rajshahi, Bangladesh.

(e-mail: rawshanarak@gmail.com) Julekha Khatun

Department of Radiotherapy, Rajshahi

Medical College Hospital, Rajshahi, Bangladesh.

(e-mail: julekharmc@gmail.com)

Kutub Uddin Ahamed

Department of Pharmacy, Jagannath University, Dhaka, Bangladesh.

(e-mail: kutubuddinjnu@gmail.com)

\section{INTRODUCTION}

In women with bosom malignant growth who go through bosom rationing a medical procedure [1], [2], entire bosom illumination diminishes the danger of neighborhood repeat and forestall requirement for mastectomy [3]-[5]. An upgradation of a meta-investigation showed that bosom light after bosom saving a medical procedure lessens mortality from bosom cancer [6], [7] However, up to $30 \%$ of ladies in North America who go through bosom preserving a medical procedure do not go through bosom illumination, partially in view of the burden of the treatment and its cost [7], [8].

In the first preliminaries that assessed entire bosom illumination after bosom rationing a medical procedure,[9], [10], 50 Gy of radiation were generally given in 25 parts over a time of 35 days in everyday parts of 2 Gy [10], [11]. Radio biologic models recommend that a bigger day by day portion (hypofractionation) given throughout a more limited time (sped up treatment) may be similarly as effective; this routine may likewise be advantageous for patients and less escalated than the timetable. Lower paces of neighborhood repeat, and restricted radiation-actuated horribleness have been accounted for approaches [12]. Schedules utilized in these investigations went from 40 to $44 \mathrm{~Gy}$ given in 15 to 16 portions over a 21 days' time frame, with everyday parts of 2.5 to 2.7 Gy [13], [14].

This may prompt people maintaining a strategic distance from corresponding treatment after moderate medical procedure, or superfluous maltreatment of extremist mastectomy in the underlying stages [15], which brings about an undertreatment or overtreatment in countless cases [16]. Along these lines, it is fitting to design a helpful treatment routine for the older patients while a comparable nearby control result can be accomplished. Today, albeit the current standard is moderate every day hypofractionation, there are as yet numerous patients who can't endure it and require a more adjusted treatment to their condition [17], [18]. There are other fractionation plans that can abbreviate the radiation therapy, exhibiting the equivalent viability, without expanding entanglements. Aside improvement in personal satisfaction [19], [20].

Previously we detailed the 60-month consequences preliminary entire chemo at a portion of 50 Gy given in 20 divisions over a time of 5 weaks was contrasted and sped up [21], hypo fractionated entire bosom illumination, at a portion of 42.5 Gy given in 16 parts over a time of 22 days, after bosom rationing a medical procedure in women lymph hub negative breast carcinoma [22], [23]. Repetition rate was 3\% and restorative results, reflection radiation-related 
horribleness, were comparative in the two gatherings. Harmful impacts of radiation, specifically poisonousness identified with huge portions per division, can increment over time; this raised worries that hindered the general appropriation of the hypo fractionated approach [17]. Here, we depict the consequences of our primary at a middle development of 36 months [24]-[26].

\section{MethodS AND MATERIALS}

\section{A. Treatment Patterns}

Randomization was performed by age $<50$ years or $\geq 50$ years, tumor size $\leq 2 \mathrm{~cm}$ or $>2 \mathrm{~cm}$, methodical adjuvant treatment with tamoxifen, any chemotherapy, or no treatment, and core interest [27]-[29]. A PC made randomization plan given out patients to standardized full chest enlightenment at a segment of 50 Gy given less than 1minute sections throughout a 5 weeks or ongoing, hypo fractionated whole chest light at a segment of 42.5 Gy given in 16 divisions throughout a period of 3 weeks. Therapy was passed on through two conflicted digressive fields, with treatment given each 5 days [30]-[32].

\section{B. Patients}

Nuances of the examination setup have been portrayed somewhere else. Momentarily, the individuals had prominent chest cancerous which was negatively centered and treat through chest apportioning an operation and axillary examination [33],[34]. Shirking measures were nosy disorder or ductal cancer in situ including the edges of extraction, tumors that were greater than $5 \mathrm{~cm}$ in broadness, and a chest width of more than $25 \mathrm{~cm}$ at the back line of the normal and level unessential bars, which could construct the heterogeneity of the radiation part to the chest [35], [36]. Taking an interest was the Cancerous sickness centers in Dhaka, Delhe, Chittagong, and Cancer institute; Rajshahi Medical Collage Hospital [37], [38]. The assessment was supported by the overview driving body of partaking spot, and all patients gave taught consent form. Every maker going for data arrangement, data collection, and analysis of the examination [39], [40].

\section{Follow-up and Outcomes}

After culmination of cancer therapy, ill parsons were seen as expected for an exceptionally significant time-frame and thereafter monthly. In visiting time, lots of encounters ware taken. If a part couldn't go to a booked ensuing visit, the family expert was reached concerning rehash, new threatening development, or destruction [41]-[43]. Mammography was played out a half year after cancer therapy and a while later monthly. Later unsafe radiation was overviewed 12, 24 and 36 months after randomization. Therapeutic benchmark was measured and at these identical following schedule in centers [44]-[46].

Initial result was close by rehash of prominent dangerous development in the chest. Assistant results were obscure rehash of chest illness; secondary tumors, as well as ipsilateral chest harm; chest maquillage; overdue noxious effects of radiation; and end. Rational infection, a cardiovascular disease, or another explanation was moreover assessing as a likely marker of radiotherapy-related terribleness. Two expertise were singly interceded the justification demise with work portfolio. Another one specialist was explored the case if any miscommunication happened [47]-[49].

Noxious outcome of radiotherapy were reviewed by a clinical-primers support with the Late Radial lethal numbering parameter [50]-[52]. The nursing task didn't cover from the hospital-fundamentals sustain. Radiotherapy effect on skin and subcutaneous tissue were assessed on a size on scale 5 ( 0 indicating safe position, and 4 exhibiting skin lesion). A readied hospital-starters support evaluates the remedial measurement using the European organization therapeutic ranging system. Care-giver differentiated the operated chest and the unoperatic chest and investigated different parameters, including different tissue culture of the heart, and the overall helpful outcomes [53]. Attribute was explored by lower size 0 and higher size 3 . We simply disclosed the overall restorative result. Maquillage and noxious repercussion were not surveyed while rehash or an ensuing illness [54]-[56].

\section{Radiation Analysis}

The control timetable for radiotherapy compared with the non-steroidal of the hypo fractionated therapy. The pace of neighborhood repeat at 36 months in the benchmark category by $5 \%$. Based on the consequences of a previous preliminary in which the pace of nearby repeat at 3 years was $7 \%$ with the utilization of bosom illumination as contrasted and $25 \%$ with no further treatment, we acknowledged a greatest disappearance of viability by $5 \%$ rate focuses in the radiotherapy bunch. This mediocrity edge was resolved by way of meeting with radiologist. The measurement for 300 inpatients for every gathering, depended on these suppositions and a force of $70 \%$ with an uneven alpha degree of $5 \%$. The principal investigation, performed at year and a half, showed moderately low occasion charge. When all inpatients finished a 36-months appraisal then subsequent examination had arranged.

Essential examination last part was done by the aim of treatment rule. The repetition was characterized as the quantity of days from randomization to nearby repeat as a first occasion [57], [58]. Information was edited at the hour of inaccessible repeat, last contact, or passing, whichever happened first. Generally, endurance was characterized as the chance to die from any reason. Paces of nearby repeat and generally speaking endurance were resolved by the KaplanMeier strategy [59]-[61]. The distinction in the 3-year nearby repeat remuneration were determined with double sided and just around $100 \%$ certainty span through the Greenwood recipe. The non-inferiority speculation was tried with the utilization of a $\mathrm{z}$-test counterbalance by the no inferiority edge [62], [63]. We utilized the log-rank test to analyze in general endurance in gatherings, by utilizing corresponding dangers representation to assess the uniformity of reception impacts by examine for associations betwixt the therapeutic gathering and subsection of scrutiny. malignancy size was articulate as more modest within $2 \mathrm{~cm}$ bigger or lower for subsection [64]-[66]. 


\section{RESULTS}

\section{A. Investigation Contributor}

In the six months of 2017 to 2020,600 cases went through for randomization, 320 cases went to the hypofractionated radiation therapy and others are allocated to the benchmark group. $30 \%$ womens showed more youthful comparing to 50 years age; $35 \%$ of them carrying malignancy which were 2 $\mathrm{cm}$ or bigger in breadth; estrogen-receptor-negative infection consumed by $22 \%$ of the patients and $20.2 \%$ of them were facing very sickness; $43.1 \%$ got subsidiary tamoxifen, and $7.9 \%$ had gotten subordinate foundational treatment, most generally cyclophosphamide, methotrexate, and fluorouracil. 21 sufferers did not get the predetermined radiation routine (2\%). Each of the 600 patients were remembered for the adequacy investigation; 95 victims were disoriented to investigation. For the poisonousness investigation, 150 and 150 valetudinarians were consecutively assessed at 1.5 and 3 years.

\section{A}

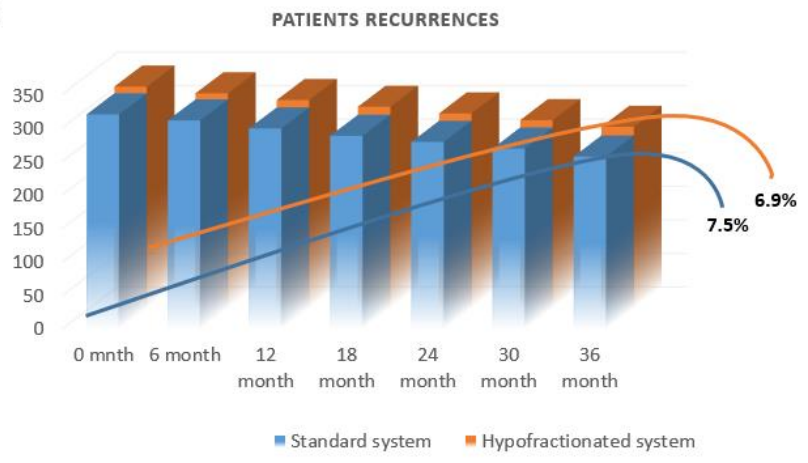

B

PERCENT OF SURVIVAL

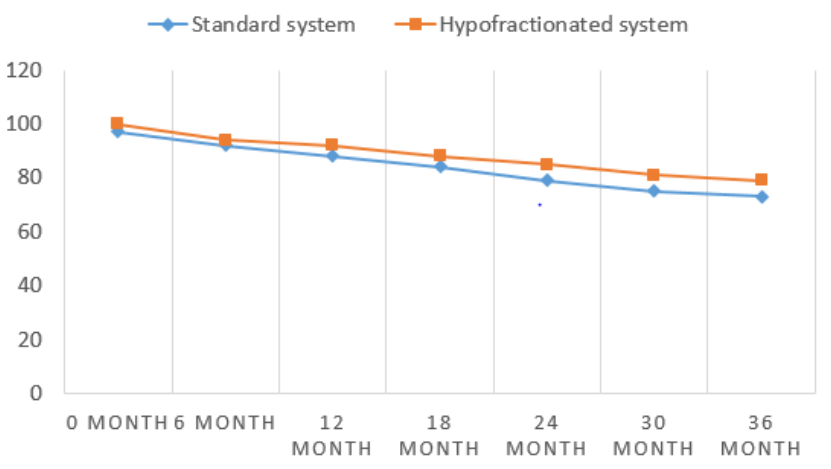

Fig. 1. Hypofractionated of Radiation Therapy as Compared with Standard System.

\section{B. Nearby Repeat}

Neighborhood obtrusive repeat of bosom malignancy was the first occasion in quite a while (100 patients in the benchmark group and 102 patients in the hypofractionatedradiation bunch). The total rate of neighborhood repeat was very comparative in the two gatherings (Fig. 1A). At 3 years, the aggregate occurrence of nearby repeat was $7.2 \%$ in the benchmark group as contrasted and $6.9 \%$ in the hypofractionated-radiation bunch (outright distinction, 0.5 rate focuses; $95 \% \mathrm{CI}$ ); that is, we have $92.5 \%$ certainty that the hypofractionated routine is no more regrettable than the control routine by 2.5 rate focuses. The trial of the invalid speculation that the sped-up routine would be more terrible than the standard treatment was dismissed for noninferiority
$(\mathrm{P}<0.001)$. Notwithstanding the 83 intrusive repeats, there were 13 instances of noninvasive nearby repeats (i.e., ductal carcinoma in situ): 3 cases in the benchmark group and 3 in the hypofractionated-radiation bunch. At 10 years, the total rate of intrusive or noninvasive neighborhood repeat was $7.5 \%$ in the benchmark group as contrasted and $6.9 \%$ in the hypofractionated-radiation bunch. Endurance pace of two transmitted gatherings exceptionally shut from one another. A subgroup investigation showed that the treatment impact was comparative, paying little heed to the patient's age, tumor size, Tumor grade, estrogen-receptor status, or use or nonuse of fundamental treatment (Fig. 2). The hypofractionated routine seemed, by all accounts, to be less powerful in patients with high-grade tumors; in this subgroup, the total occurrence of neighborhood repeat at 3 years was $5.2 \%$ in the benchmark group as contrasted and $16.2 \%$ in the hypofractionated-radiation bunch.

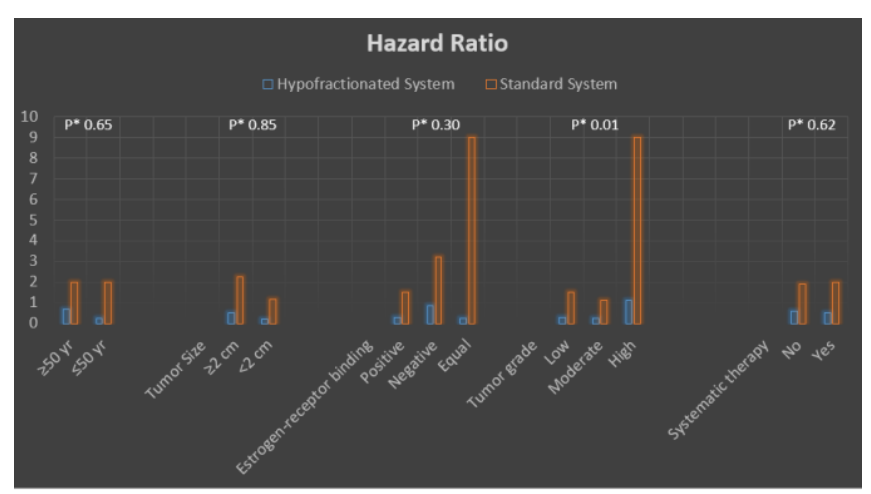

Fig. 2. Different Groups Breast Cancer Patients Hazard Ratios.

\section{Mortality}

There were 160 passings ( 86 in the benchmark group and 74 in the hypofractionated-radiation bunch). The likelihood of endurance over the long run was comparative in the two gatherings $(\mathrm{P}=0.72)$ (Fig. 1B). At 3 years, the likelihood of endurance was $80 \%$ in the benchmark group as contrasted and $85 \%$ in the hypofractionated-radiation bunch. In the benchmark group of 300 patients, 40 passings were identified with malignancy $(13.3 \%), 10$ were identified with heart illness $(3.33 \%)$, and 20 were because of different causes $(6.66 \%)$. In the hypofractionated-radiation gathering of 300 patients, 38 passings were identified with malignant growth $(12.66 \%), 12$ were identified with cardiovascular sickness (3\%), and 31 were because of different causes (10\%). No huge contrasts were recognized between the gatherings $(\mathrm{P}=0.65)$.

\section{Poisonous Effects of Radiation and Cosmetic Outcome}

Fig. 3 shows the level of patients with harmful impacts of light of the skin and subcutaneous tissue multi months and three years after randomization. Neither evaluation 4 skin ulceration nor delicate tissue rot was noticed. Albeit the occurrence of late poisonous impacts of radiation expanded over the subsequent period, at 3 years, the extent of ladies with grade 3 radiation-related dreariness was $5 \%$ or less. At 3 years, there were no skin harmful impacts in $85.3 \%$ of ladies in the benchmark group as contrasted and $76.8 \%$ of ladies in the hypofractionated-radiation bunch. There were no poisonous impacts in subcutaneous tissue in $46.5 \%$ of ladies 
in the benchmark group as contrasted and $49.2 \%$ of ladies in the hypofractionated-radiation bunch.

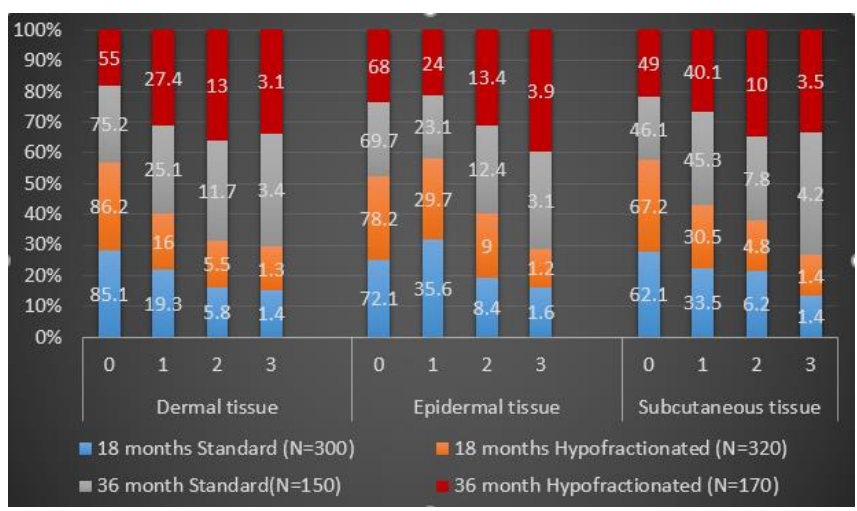

Fig. 3. Toxicity of Radiotherapy on Skin Tissue.

Fig. 4 shows the corrective result at pattern, 1.5 years, and 3 years. Albeit the worldwide restorative result deteriorated over the long haul, no critical contrasts were seen between the gatherings whenever. At 3 years, $75.6 \%$ of ladies in the benchmark group as contrasted and $72.2 \%$ of ladies in the hypofractionated-radiation bunch, had a great or great corrective result. The rehashed measures strategic relapse investigation proposed that the restorative result was influenced when from randomization just as by the patient's age and tumor size, however there was no communication with treatment.

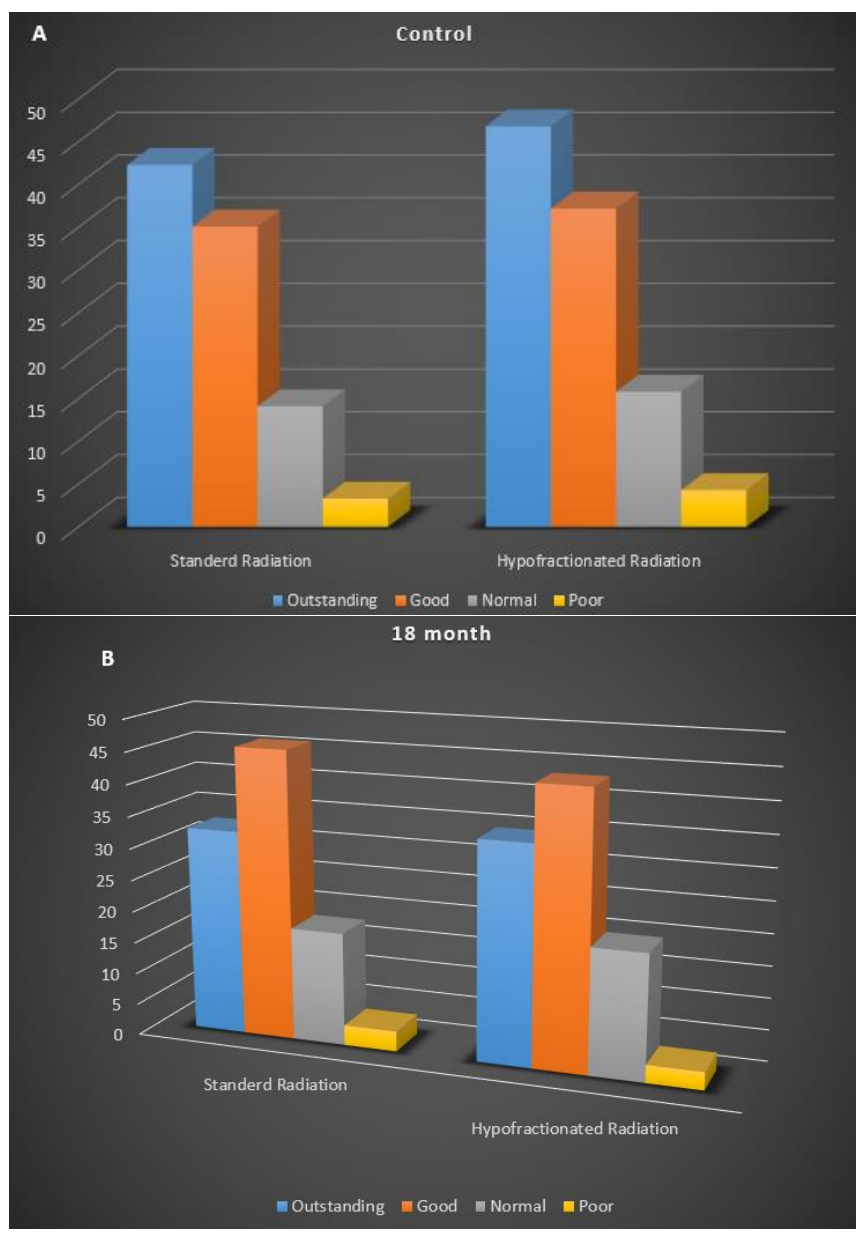

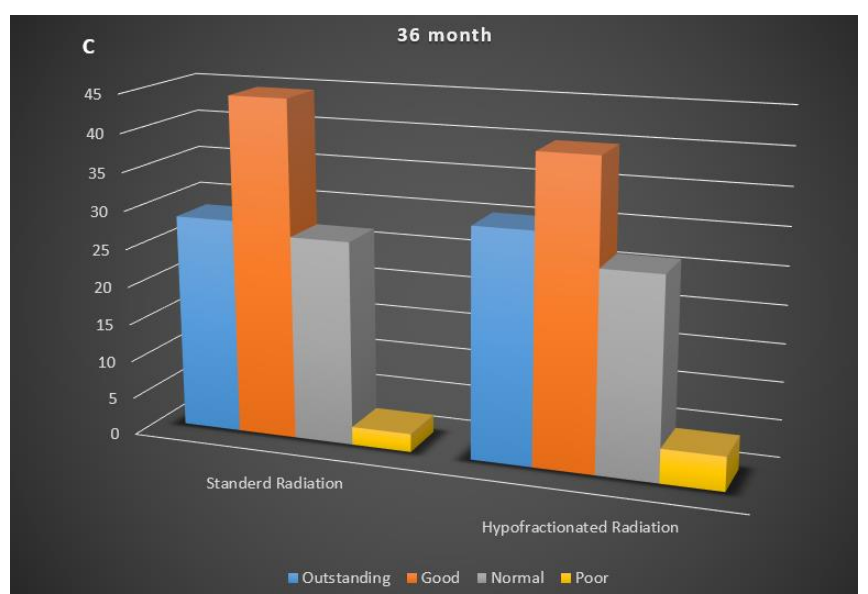

Fig. 4. Different time points Data received from the hypofractionated System and Internal Comparison.

\section{DISCUSSION}

Our objective was to decide if entire bosom illumination after bosom rationing a medical procedure could be protected and viable when managed in a bigger portion for every division and in a more limited timeframe than in the standard timetable [67]-[70]. The 6-year consequences of our preliminary revealed recently showed no critical contrasts in adequacy or poisonousness between the radiation regimens. Nevertheless, in light of the fact that radiation-related microvascular harm increments over the long haul, matter of worry that harmful impacts of radiotherapy related with the hypo fractionated routine could developed [71], [72].

Recent 4 years' middle development phase, two assemblies was the lowest among repeated 3 years of neighborhood. The standard was not comparable with the hypo fractionated radiation. The investigative subspecies investigation, hypo fractionation had all the earmarks of being less compelling for exceptional sarcoma comparing with poor-quality sarcoma [73]-[77]. The following experiments might be a successive result, yet this might rather mirror an alternate inalienable radiation affectability of superlative sarcoma or idiomatic subgroup of bosom malignant growth which were related to superlative sarcoma.

Long term radiotherapy may cause skin tissue damage [78], Epidermal tissue prompting loss of volume and withdrawal of the bosom [79], all of which can antagonistically influence the restorative result. We saw a deterioration of the restorative result over the long run, which agreed with the expansion in harmful effect [80], [81]. Nonetheless, none of the poisonous impacts observed in case of lady patients whom were got sped up, hypo fractionated radio therapy as contrasted and the individuals who got the standard routine. Albeit more established age and enormous tumor size were related with a more awful restorative result, the results of the hypofractionated routine were like those of the standard routine [82], [31], [36], [40].

Left sided bosom illumination done entirely, related with a marginally expanded danger of expiring owing to cardiovascular disease. Radiation treatment cannot be normal until 3 years or more. In our preliminary, we noticed no huge distinction in by and large endurance among more than two treatment gatherings. In the time of 4years, not many cardiovascular analogous passing was noticed. There was no 
expansion happened in sufferer who got the hypo fractionated routine.

The likely constraints of our investigation ought to be noted. The preliminary was confined to ladies who had hub negative, intrusive bosom malignant growth with clear edges of extraction after lumpectomy. In spite of the fact that we included micro-waves cancer patients and dactyl gram lady's carcinoma patients.[88], this isn't altogether certain outcomes that might be inferred to women who bears dactyl gram cancer [89], [90]. We did exclude ladies with hub positive bosom disease, and consequently our outcomes are not pertinent to patients for whom nodal illumination is arranged. Ladies with huge bosoms were additionally excluded, and few ladies got adjuvant chemotherapy [91], [92]. These kinds of inmates possibly expanded danger restorative result along with standard chemotherapy, so hypo fractionation would prompt a result that would be any more awful than that with standard treatment. We didn't utilize support illumination, on the grounds that at the time the examination was started, the adequacy of lift light had not been exhibited and we needed to stay away from the jumbling impact that help illumination could have on nearby repeat or bosom cosmesis [93]-[95]. Since the fruition of our preliminary, the consequences of different preliminaries, offering help for the utilization of lift light [96], [97], and stimulant radio therapy was utilized more frequently than in our primarily. Until this point, no expansion in poisonous impacts in these preliminaries has been accounted for.

Week by week hypofractionated radiation treatment is an attainable and helpful choice for patients with cutting edge bosom malignant growth who don't endure an everyday treatment [98]-[101]. It is a protected treatment methodology with comparative endurance and neighborhood control results. The results are likewise adequate. Similarly, as with the week by week hypofractionation plan, the decrease of all out-time treatment may improve patients' personal satisfaction [102], [103].

Taking everything into account, our drawn out outcomes offer help for the utilization of sped up, hypofractionated, entire bosom illumination in chosen ladies with hub negative bosom disease after bosom rationing a medical procedure [104]-[106]. For ladies with bosom disease who are like the cases in this primarily, a shortened line of emission treatment might be show high advantegious factors and make low rate of cost during standard therapy. This treatment pattern accessibility might be increased and it coud be popuar among the women who have cancer.

\section{ACKNOWLEDGMENT}

This research work supported by Department of Radiotherapy; Rajshahi Medical College Hospital. Research grant number is RMCHO111055.

\section{REFERENCES}

[1] B. Fisher, J.-H. Jeong, S. Anderson, J. Bryant, E. R. Fisher, and N. Wolmark, "Twenty-five-year follow-up of a randomized trial comparing radical mastectomy, total mastectomy, and total mastectomy followed by irradiation.," N. Engl. J. Med., vol. 347, no. 8, pp. 567-575, Aug. 2002, doi: 10.1056/NEJMoa020128.
[2] B. Fisher et al., "Eight-year results of a randomized clinical trial comparing total mastectomy and lumpectomy with or without irradiation in the treatment of breast cancer.," N. Engl. J. Med., vol. 320, no. 13, pp. 822-828, Mar. 1989, doi: 10.1056/NEJM198903303201302.

[3] A. Bhatt, K. Sowards, G. Bhatt, A. Freeman, and A. Dragun, "Impact of interfraction seroma collection on breast brachytherapy dosimetry a mathematical model.," J. Contemp. Brachytherapy, vol. 4, no. 2, pp. 101-105, Jun. 2012, doi: 10.5114/jcb.2012.29366.

[4] S. W. Yoon et al., "Per-fraction positional and dosimetric performance of prone breast tangential radiotherapy on HalcyonTM linear accelerator assessed with daily rapid kilo-voltage cone beam computed tomography: a single-institution pilot study.," Radiat. Oncol., vol. 15, no. 1 , p. 258 , Nov. 2020, doi: 10.1186/s13014-020-01700-6.

[5] G. Curigliano et al., "De-escalating and escalating treatments for earlystage breast cancer: the St. Gallen International Expert Consensus Conference on the Primary Therapy of Early Breast Cancer 2017.,' Ann. Oncol. Off. J. Eur. Soc. Med. Oncol., vol. 28, no. 8, pp. 17001712, Aug. 2017, doi: 10.1093/annonc/mdx308.

[6] A. Gupta, N. Ohri, and B. G. Haffty, "Hypofractionated radiation treatment in the management of breast cancer.," Expert Rev. Anticancer Ther., vol. 18, no. 8, pp. 793-803, Aug. 2018, doi: 10.1080/14737140.2018.1489245.

[7] J. Y. Lin et al., "Full axillary lymph node dissection and increased breast epidermal thickness 1 year after radiation therapy for breast cancer.,”J. Surg. Oncol., vol. 120, no. 8, pp. 1397-1403, Dec. 2019 , doi: $10.1002 /$ jso. 25757 .

[8] J. Boyages and L. Baker, "Evolution of radiotherapy techniques in breast conservation treatment." Gland Surg., vol. 7, no. 6, pp. 576-595, Dec. 2018, doi: 10.21037/gs.2018.11.10.

[9] N. Aibe et al., "Results of a nationwide survey on Japanese clinical practice in breast-conserving radiotherapy for breast cancer." J. Radiat Res., vol. 60, no. 1, pp. 142-149, Jan. 2019, doi: 10.1093/jrr/rry095.

[10] J. Sanz et al., "Once-Weekly Hypofractionated Radiotherapy for Breast Cancer in Elderly Patients: Efficacy and Tolerance in 486 Patients." Biomed Res. Int., vol. 2018, p. 8321871, 2018, doi: 10.1155/2018/8321871.

[11] S. F. Shaitelman et al., "Acute and Short-term Toxic Effects of Conventionally Fractionated vs Hypofractionated Whole-Breast Irradiation: A Randomized Clinical Trial.," JAMA Oncol., vol. 1, no. 7, pp. 931-941, Oct. 2015, doi: 10.1001/jamaoncol.2015.2666.

[12] S. Chatterjee and S. Chakraborty, "Hypofractionated radiation therapy comparing a standard radiotherapy schedule (over 3 weeks) with a novel 1-week schedule in adjuvant breast cancer: an open-label randomized controlled study (HYPORT-Adjuvant)-study protocol for a multicentre, randomized ," Trials, vol. 21 , no. 1, p. 819 , Sep. 2020 , doi: 10.1186/s13063-020-04751-y.

[13] H. Kim et al., "Prognostic Impact of Elective Supraclavicular Nodal Irradiation for Patients with N1 Breast Cancer after Lumpectomy and Anthracycline Plus Taxane-Based Chemotherapy (KROG 1418): A Multicenter Case-Controlled Study.," Cancer Res. Treat., vol. 49, no. 4, pp. 970-980, Oct. 2017, doi: 10.4143/crt.2016.382.

[14] E. F. Gillespie et al., "Geographic Disparity in the Use of Hypofractionated Radiation Therapy among Elderly Women Undergoing Breast Conservation for Invasive Breast Cancer.” Int. J. Radiat. Oncol. Biol. Phys., vol. 96, no. 2, pp. 251-258, Oct. 2016, doi: 10.1016/j.ijrobp.2016.05.006.

[15] K. J. Ray, N. R. Sibson, and A. E. Kiltie, "Treatment of Breast and Prostate Cancer by Hypofractionated Radiotherapy: Potential Risks and Benefits.” Clin. Oncol. (R. Coll. Radiol)., vol. 27, no. 7, pp. 420 426, Jul. 2015, doi: 10.1016/j.clon.2015.02.008.

[16] J.-C. Trone et al., "Assessment of non-inferiority with meta-analysis: example of hypofractionated radiation therapy in breast and prostate cancer.," Sci. Rep., vol. 10, no. 1, p. 15415, Sep. 2020, doi: 10.1038/s41598-020-72088-2.

[17] B. E. Hickey, M. Lehman, D. P. Francis, and A. M. See, "Partial breast irradiation for early breast cancer.," Cochrane database Syst. Rev., vol. 7, no. 7, p. CD007077, Jul. 2016, doi: 10.1002/14651858.CD007077.pub3.

[18] G. Henke et al., "Tailored axillary surgery with or without axillary lymph node dissection followed by radiotherapy in patients with clinically node-positive breast cancer (TAXIS): study protocol for a multicenter, randomized phase-III trial.," Trials, vol. 19, no. 1, p. 667 Dec. 2018, doi: 10.1186/s13063-018-3021-9.

[19] F. Sedlmayer et al., "Intraoperative radiotherapy (IORT) as boost in breast cancer.” Radiat. Oncol., vol. 12, no. 1, p. 23, Jan. 2017, doi: 10.1186/s13014-016-0749-9.

[20] M. S. Moran et al., "Society of Surgical Oncology-American Society for Radiation Oncology consensus guideline on margins for breastconserving surgery with whole-breast irradiation in stages I and II 
invasive breast cancer.” Int. J. Radiat. Oncol. Biol. Phys., vol. 88, no. 3, pp. 553-564, Mar. 2014, doi: 10.1016/j.ijrobp.2013.11.012.

[21] J. E. Bekelman et al., "Uptake and costs of hypofractionated vs conventional whole breast irradiation after breast conserving surgery in the United States, 2008-2013.," JAMA, vol. 312, no. 23, pp. 2542 2550, Dec. 2014, doi: 10.1001/jama.2014.16616.

[22] F. De Rose et al., "Phase II trial of hypofractionated VMAT-based treatment for early stage breast cancer: 2-year toxicity and clinical results." Radiat. Oncol., vol. 11, no. 1, p. 120, Sep. 2016, doi: 10.1186/s13014-016-0701-z.

[23] S.-S. Liau, M. Cariati, D. Noble, C. Wilson, and G. C. Wishart, "Audit of local recurrence following breast conservation surgery with 5-mm target margin and hypofractionated 40-Gray breast radiotherapy for invasive breast cancer.," Ann. R. Coll. Surg. Engl., vol. 92, no. 7, pp. 562-568, Oct. 2010, doi: 10.1308/003588410X12699663903476.

[24] N. Houssami, P. Macaskill, M. L. Marinovich, and M. Morrow, "The association of surgical margins and local recurrence in women with early-stage invasive breast cancer treated with breast-conserving therapy: a meta-analysis.," Ann. Surg. Oncol., vol. 21, no. 3, pp. $717-$ 730, Mar. 2014, doi: 10.1245/s10434-014-3480-5

[25] Y.-J. Kim, K. H. Shin, and K. Kim, "Omitting Adjuvant Radiotherapy for Hormone Receptor-Positive Early-Stage Breast Cancer in Old Age: A Propensity Score Matched SEER Analysis.," Cancer Res. Treat., vol. 51, no. 1, pp. 326-336, Jan. 2019, doi: 10.4143/crt.2018.163.

[26] M. Lagendijk et al., "TUmor-volume to breast-volume RAtio for improving COSmetic results in breast cancer patients (TURACOS); a randomized controlled trial.," BMC Cancer, vol. 17, no. 1, p. 336, May 2017, doi: 10.1186/s12885-017-3280-y.

[27] A. Ho and M. Morrow, "The evolution of the locoregional therapy of breast cancer." Oncologist, vol. 16, no. 10, pp. 1367-1379, 2011, doi 10.1634/theoncologist.2011-0223.

[28] J. B. Yu et al., "Peer Influence on Physician Use of Shorter Course External Beam Radiation Therapy for Patients with Breast Cancer." Pract. Radiat. Oncol., vol. 10, no. 2, pp. 75-83, 2020, doi: 10.1016/j.prro.2019.11.001.

[29] M. Morrow et al., "Society of Surgical Oncology-American Society for Radiation Oncology-American Society of Clinical Oncology Consensus Guideline on Margins for Breast-Conserving Surgery with Whole-Breast Irradiation in Ductal Carcinoma In Situ.," Ann. Surg. Oncol., vol. 23, no. 12, pp. 3801-3810, Nov. 2016, doi: 10.1245/s10434-016-5449-z.

[30] A. Nagai, Y. Shibamoto, M. Yoshida, K. Inoda, and Y. Kikuchi, "Intensity-modulated radiotherapy using two static ports of tomotherapy for breast cancer after conservative surgery: dosimetric comparison with other treatment methods and 3-year clinical results." J. Radiat. Res., vol. 58, no. 4, pp. 529-536, Jul. 2017, doi: $10.1093 / \mathrm{jrr} / \mathrm{rrw} 132$

[31] A. J. Khan et al., "Hypofractionated Postmastectomy Radiation Therapy Is Safe and Effective: First Results from a Prospective Phase II Trial.," J. Clin. Oncol. Off. J. Am. Soc. Clin. Oncol., vol. 35, no. 18, pp. 2037-2043, Jun. 2017, doi: 10.1200/JCO.2016.70.7158.

[32] S. R. Stecklein et al., "Prospective Comparison of Toxicity and Cosmetic Outcome after Accelerated Partial Breast Irradiation with Conformal External Beam Radiotherapy or Single-Entry Multilumen Intracavitary Brachytherapy.," Pract. Radiat. Oncol., vol. 9, no. 1, pp. e4-e13, Jan. 2019, doi: 10.1016/j.prro.2018.08.003.

[33] J. S. Haviland et al., "Late normal tissue effects in the arm and shoulder following lymphatic radiotherapy: Results from the UK START (Standardisation of Breast Radiotherapy) trials." Radiother. Oncol. J. Eur. Soc. Ther. Radiol. Oncol., vol. 126, no. 1, pp. 155-162, Jan. 2018, doi: 10.1016/j.radonc.2017.10.033.

[34] C. M. Fisher and R. Rabinovitch, "Frontiers in radiotherapy for earlystage invasive breast cancer." J. Clin. Oncol. Off. J. Am. Soc. Clin. Oncol., vol. 32, no. 26, pp. 2894-2901, Sep. 2014, doi: 10.1200/JCO.2014.55.1184.

[35] J. Landercasper et al., "The American Society of Breast Surgeons and Quality Payment Programs: Ranking, Defining, and Benchmarking More Than 1 Million Patient Quality Measure Encounters.," Ann. Surg. Oncol., vol. 24, no. 10, pp. 3093-3106, Oct. 2017, doi: 10.1245/s10434-017-5940-1.

[36] L. Liu et al., "Comparing hypofractionated to conventional fractionated radiotherapy in postmastectomy breast cancer: a meta-analysis and systematic review." Radiat. Oncol., vol. 15, no. 1, p. 17, Jan. 2020, doi: 10.1186/s13014-020-1463-1.

[37] D. B. Page et al., "Two may be better than one: PD-1/PD-L1 blockade combination approaches in metastatic breast cancer." NPJ breast cancer, vol. 5, p. 34, 2019, doi: 10.1038/s41523-019-0130-x.

[38] L. He, Q. Wu, J. Xiong, Z. Su, B. Zhang, and Y. Song, "Do early HER2-overexpression breast cancer patients benefit from undergoing neoadjuvant trastuzumab and mastectomy? A meta-analysis.," Cancer
Manag. Res., vol. 11, pp. 8043-8054, 2019, doi: 10.2147/CMAR.S208319.

[39] G. M. Freedman et al., "Five-year local control in a phase II study of hypofractionated intensity modulated radiation therapy with an incorporated boost for early stage breast cancer.," Int. J. Radiat. Oncol. Biol. Phys., vol. 84, no. 4, pp. 888-893, Nov. 2012, doi: 10.1016/j.ijrobp.2012.01.091.

[40] S. Tian et al., "Comparison of Mammographic Changes Across Three Different Fractionation Schedules for Early-Stage Breast Cancer.," Int. J. Radiat. Oncol. Biol. Phys., vol. 95, no. 2, pp. 597-604, Jun. 2016, doi: 10.1016/j.ijrobp.2016.01.056.

[41] B. M. Syed et al., "Oestrogen receptor negative early operable primary breast cancer in older women-Biological characteristics and long-term clinical outcome." PLoS One, vol. 12, no. 12, p. e0188528, 2017, doi: 10.1371/journal.pone.0188528

[42] S. M. Shirvani et al., "Trends in Local Therapy Utilization and Cost for Early-Stage Breast Cancer in Older Women: Implications for Payment and Policy Reform.” Int. J. Radiat. Oncol. Biol. Phys., vol. 95, no. 2, pp. 605-616, Jun. 2016, doi: 10.1016/j.ijrobp.2016.01.059.

[43] J. Landercasper et al., "Measures of Appropriateness and Value for Breast Surgeons and Their Patients: The American Society of Breast Surgeons Choosing Wisely (®) Initiative.," Ann. Surg. Oncol., vol. 23, no. 10 , pp. 3112-3118, Oct. 2016, doi: 10.1245/s10434-016-5327-8.

[44] M. Doré, B. Cutuli, P. Cellier, L. Campion, and M. Le Blanc, "Hypofractionated irradiation in elderly patients with breast cancer after breast conserving surgery and mastectomy: Analysis of 205 cases." Radiat. Oncol., vol. 10, p. 161, Aug. 2015, doi 10.1186/s13014-015-0448-y.

[45] P. T. Truong, I. A. Olivotto, T. J. Whelan, and M. Levine, "Clinical practice guidelines for the care and treatment of breast cancer: 16 . Locoregional post-mastectomy radiotherapy." C. Can. Med. Assoc. J. = J. l'Association medicale Can., vol. 170, no. 8, pp. 1263-1273, Apr. 2004, doi: 10.1503/cmaj.1031000.

[46] A. J. Khan et al., "Three-Fraction Accelerated Partial Breast Irradiation (APBI) Delivered with Brachytherapy Applicators Is Feasible and Safe: First Results From the TRIUMPH-T Trial.” Int. J. Radiat. Oncol. Biol. Phys., vol. 104, no. 1, pp. 67-74, May 2019, doi: 10.1016/j.ijrobp.2018.12.050.

[47] G. Tortorelli et al., "Standard or hypofractionated radiotherapy in the postoperative treatment of breast cancer: a retrospective analysis of acute skin toxicity and dose inhomogeneities.," BMC Cancer, vol. 13, p. 230, May 2013, doi: 10.1186/1471-2407-13-230.

[48] J. J. Cuaron, S. M. MacDonald, and O. Cahlon, "Novel applications of proton therapy in breast carcinoma." Chinese Clin. Oncol., vol. 5, no. 4, p. 52, Aug. 2016, doi: 10.21037/cco.2016.06.04.

[49] H.-J. Wu and P.-Y. Chu, "Recent Discoveries of Macromolecule- and Cell-Based Biomarkers and Therapeutic Implications in Breast Cancer.," Int. J. Mol. Sci., vol. 22, no. 2, Jan. 2021, doi 10.3390/ijms22020636.

[50] I. J. Boero et al., "The impact of radiotherapy costs on clinical outcomes in breast cancer.” Radiother. Oncol. J. Eur. Soc. Ther. Radiol. Oncol., vol. 117, no. 2, pp. 393-399, Nov. 2015, doi 10.1016/j.radonc.2015.10.004.

[51] R. Rabinovitch et al., "RTOG 95-17, a Phase II trial to evaluate brachytherapy as the sole method of radiation therapy for Stage I and II breast carcinoma--year-5 toxicity and cosmesis.," Brachytherapy, vol. 13, no. 1. pp. 17-22, 2014, doi: 10.1016/j.brachy.2013.08.002.

[52] Y.-J. Cheng et al., "Long-Term Cardiovascular Risk after Radiotherapy in Women with Breast Cancer.," J. Am. Heart Assoc., vol. 6, no. 5, May 2017, doi: 10.1161/JAHA.117.005633.

[53] G. Valdivia, Á. Alonso-Diez, D. Pérez-Alenza, and L. Peña, "From Conventional to Precision Therapy in Canine Mammary Cancer: A Comprehensive Review." Front. Vet. Sci., vol. 8, p. 623800, 2021, doi $10.3389 /$ fvets.2021.623800.

[54] L. Tagliaferri et al., "Could a Personalized Strategy Using Accelerated Partial Breast Irradiation be an Advantage for Elderly Patients? A Systematic Review of the Literature and Multidisciplinary Opinion.," J. Oncol., vol. 2020, p. 3928976, 2020, doi: 10.1155/2020/3928976.

[55] S. M. Buszek et al., "Lumpectomy plus Hormone or Radiation Therapy Alone for Women Aged 70 Years or Older with Hormone ReceptorPositive Early Stage Breast Cancer in the Modern Era: An Analysis of the National Cancer Database.” Int. J. Radiat. Oncol. Biol. Phys., vol. 105, no. 4, pp. 795-802, Nov. 2019, doi: 10.1016/j.ijrobp.2019.07.052.

[56] K. J. Borm et al., "Effect of hypofractionation on the incidental axilla dose during tangential field radiotherapy in breast cancer.' Strahlenther. Onkol., vol. 196, no. 9, pp. 771-778, Sep. 2020, doi: 10.1007/s00066-020-01636-6.

[57] L. He, Y. Lv, Y. Song, and B. Zhang, "The prognosis comparison of different molecular subtypes of breast tumors after radiotherapy and the 
intrinsic reasons for their distinct radiosensitivity.," Cancer Manag. Res., vol. 11, pp. 5765-5775, 2019, doi: 10.2147/CMAR.S213663.

[58] A. Wöckel et al., "Interdisciplinary Screening, Diagnosis, Therapy and Follow-up of Breast Cancer. Guideline of the DGGG and the DKG (S3Level, AWMF Registry Number 032/045OL, December 2017) - Part 2 with Recommendations for the Therapy of Primary, Recurrent and Advanced B," Geburtshilfe Frauenheilkd., vol. 78, no. 11, pp. 10561088, Nov. 2018, doi: 10.1055/a-0646-4630.

[59] D. Krug et al., "Current controversies in radiotherapy for breast cancer." Radiat. Oncol., vol. 12, no. 1, p. 25, Jan. 2017, doi: 10.1186/s13014-017-0766-3.

[60] K. Dias et al., "Claudin-Low Breast Cancer; Clinical \& Pathological Characteristics." PLoS One, vol. 12, no. 1, p. e0168669, 2017, doi 10.1371/journal.pone.0168669.

[61] M. Brandão et al., "Healthcare use and costs in early breast cancer: a patient-level data analysis according to stage and breast cancer subtype." ESMO open, vol. 5, no. 6, p. e000984, Nov. 2020, doi: 10.1136/esmoopen-2020-000984.

[62] T. A. Koulis, A. Dang, C. Speers, and R. A. Olson, "Factors affecting radiotherapy prescribing patterns in the post-mastectomy setting.," Curr. Oncol., vol. 25, no. 2, pp. e146-e151, Apr. 2018, doi: $10.3747 /$ co. 25.3773

[63] P. Ciammella et al., "Toxicity and cosmetic outcome of hypofractionated whole-breast radiotherapy: predictive clinical and dosimetric factors." Radiat. Oncol., vol. 9, p. 97, Apr. 2014, doi 10.1186/1748-717X-9-97.

[64] G. G. Hanna and A. M. Kirby, "Intraoperative radiotherapy in early stage breast cancer: potential indications and evidence to date.," $\mathrm{Br}$. J Radiol., vol. 88, no. 1049, p. 20140686, May 2015, doi: 10.1259 /bjr.20140686.

[65] M. Guenzi et al., "Hypofractionated irradiation of infra-supraclavicular lymph nodes after axillary dissection in patients with breast cancer post-conservative surgery: impact on late toxicity." Radiat. Oncol., vol. 10, p. 177, Aug. 2015, doi: 10.1186/s13014-015-0480-y.

[66] H. Kim et al., "Optimal radiation dose for patients with one to three lymph node positive breast cancer following breast-conserving surgery and anthracycline plus taxane-based chemotherapy: A retrospective multicenter analysis (KROG 1418).," Oncotarget, vol. 8, no. 1, pp 1796-1804, Jan. 2017, doi: 10.18632/oncotarget.12882.

[67] H. S. Choi, H. S. Jang, K. M. Kang, and B.-O. Choi, "Symptom palliation of hypofractionated radiotherapy for patients with incurable inflammatory breast cancer." Radiat. Oncol., vol. 14, no. 1, p. 110, Jun. 2019, doi: 10.1186/s13014-019-1320-2

[68] W. Budach et al., "DEGRO practical guidelines for radiotherapy of breast cancer V: Therapy for locally advanced and inflammatory breast cancer, as well as local therapy in cases with synchronous distant metastases." Strahlenther. Onkol., vol. 191, no. 8, pp. 623-633, Aug. 2015, doi: 10.1007/s00066-015-0843-1.

[69] K. Karasawa et al., "A Phase I clinical trial of carbon ion radiotherapy for Stage I breast cancer: clinical and pathological evaluation." J Radiat. Res., vol. 60, no. 3, pp. 342-347, May 2019, doi: $10.1093 /$ jrr/rry 113 .

[70] M. A. Torres et al., "The Impact of Axillary Lymph Node Surgery on Breast Skin Thickening During and After Radiation Therapy for Breas Cancer.” Int. J. Radiat. Oncol. Biol. Phys., vol. 95, no. 2, pp. 590-596, Jun. 2016, doi: 10.1016/j.ijrobp.2016.01.030.

[71] R. Kreienberg, U.-S. Albert, M. Follmann, I. B. Kopp, T. Kühn, and A. Wöckel, "Interdisciplinary GoR level III Guidelines for the Diagnosis, Therapy and Follow-up Care of Breast Cancer: Short version - AWMF Registry No.: 032-045OL AWMF-Register-Nummer: 032-045OL Kurzversion 3.0, Juli 2012.," Geburtshilfe Frauenheilkd., vol. 73, no. 6, pp. 556-583, Jun. 2013, doi: 10.1055/s-0032-1328689.

[72] L. Feys et al., "Radiation-induced lung damage promotes breast cancer lung-metastasis through CXCR4 signaling." Oncotarget, vol. 6, no. 29 pp. 26615-26632, Sep. 2015, doi: 10.18632/oncotarget.5666.

[73] M. Maes-Carballo, L. Mignini, M. Martín-Díaz, A. Bueno-Cavanillas, and K. S. Khan, "Quality and reporting of clinical guidelines for breast cancer treatment: A systematic review.” Breast, vol. 53, pp. 201-211, Oct. 2020, doi: 10.1016/j.breast.2020.07.011.

[74] M. Gray et al., "Naturally-Occurring Canine Mammary Tumors as a Translational Model for Human Breast Cancer.” Front. Oncol., vol. 10, p. 617, 2020, doi: 10.3389/fonc.2020.00617.

[75] K. P. Valuckas, V. Atkocius, I. Kuzmickiene, E. Aleknavicius, S Liukpetryte, and V. Ostapenko, "Second malignancies following conventional or combined $252 \mathrm{Cf}$ neutron brachytherapy with external beam radiotherapy for breast cancer.," J. Radiat. Res., vol. 54, no. 5 , pp. 872-879, Sep. 2013, doi: 10.1093/jrr/rrt009.

[76] K. M. Arnold, L. M. Opdenaker, N. J. Flynn, D. K. Appeah, and J. Sims-Mourtada, "Radiation induces an inflammatory response that results in STAT3-dependent changes in cellular plasticity and radioresistance of breast cancer stem-like cells.," Int. J. Radiat. Biol. vol. 96, no. 4, pp. 434-447, Apr. 2020, doi 10.1080/09553002.2020.1705423.

[77] V. Landoni et al., "Evidence from a breast cancer hypofractionated schedule: late skin toxicity assessed by ultrasound." J. Exp. Clin. Cancer Res., vol. 32, no. 1, p. 80, Oct. 2013, doi: 10.1186/1756-996632-80.

[78] Y. Hasan, J. Waller, K. Yao, S. J. Chmura, and D. Huo, "Utilization trend and regimens of hypofractionated whole breast radiation therapy in the United States.," Breast Cancer Res. Treat., vol. 162, no. 2, pp. 317-328, Apr. 2017, doi: 10.1007/s10549-017-4120-0.

[79] C. W. Swanick et al., "Long-term Patient-Reported Outcomes in Older Breast Cancer Survivors: A Population-Based Survey Study.” Int. J. Radiat. Oncol. Biol. Phys., vol. 100, no. 4, pp. 882-890, Mar. 2018 , doi: 10.1016/j.ijrobp.2017.11.047.

[80] J. S. Chang et al., "Trends in the Application of Postmastectomy Radiotherapy for Breast Cancer With 1 to 3 Positive Axillary Nodes and Tumors $\leq 5 \mathrm{~cm}$ in the Modern Treatment Era: A Retrospective Korean Breast Cancer Society Report.," Medicine (Baltimore)., vol. 95 , no. 19, p. e3592, May 2016, doi: 10.1097/MD.0000000000003592.

[81] M. Scorsetti et al., "Phase I-II study of hypofractionated simultaneous integrated boost using volumetric modulated arc therapy for adjuvan radiation therapy in breast cancer patients: a report of feasibility and early toxicity results in the first 50 treatments.," Radiat. Oncol., vol. 7 , p. 145, Aug. 2012, doi: 10.1186/1748-717X-7-145.

[82] I. Ratosa, A. Jenko, and I. Oblak, "Breast size impact on adjuvant radiotherapy adverse effects and dose parameters in treatmen planning." Radiol. Oncol., vol. 52, no. 3, pp. 233-244, Aug. 2018, doi 10.2478/raon-2018-0026.

[83] S. Ahmed et al., "Newly discovered breast cancer susceptibility loci on 3p24 and 17q23.2.," Nat. Genet., vol. 41, no. 5, pp. 585-590, May 2009, doi: $10.1038 / \mathrm{ng} .354$

[84] S. Prathima, R. Kalyani, and S. Parimala, "Primary tubercular mastitis masquerading as malignancy." Journal of natural science, biology, and medicine, vol. 5, no. 1. pp. 184-186, Jan-2014, doi: 10.4103/09769668.127324

[85] Z. Güzelöz et al., "Treatment results in patients with ductal carcinoma in situ treated with adjuvant radiotherapy.," Turkish J. Med. Sci., vol 49, no. 4, pp. 1151-1156, Aug. 2019, doi: 10.3906/sag-1810-53

[86] C. Murphy et al., "Impact of the radiation boost on outcomes after breast-conserving surgery and radiation.” Int. J. Radiat. Oncol. Biol. Phys., vol. 81, no. 1, pp. 69-76, Sep. 2011, doi 10.1016/j.ijrobp.2010.04.067.

[87] S. Darby et al., "Effect of radiotherapy after breast-conserving surgery on 10-year recurrence and 15-year breast cancer death: meta-analysis of individual patient data for 10,801 women in 17 randomised trials.' Lancet (London, England), vol. 378, no. 9804, pp. 1707-1716, Nov 2011, doi: 10.1016/S0140-6736(11)61629-2

[88] S.-W. Lee et al., "Accelerated whole breast irradiation in early breast cancer patients with adverse prognostic features." Oncotarget, vol. 7 , no. 49, pp. 81888-81898, Dec. 2016, doi: 10.18632/oncotarget.11702.

[89] S. Ahlawat et al., "Short-Course Hypofractionated Radiation Therapy with Boost in Women with Stages 0 to IIIa Breast Cancer: A Phase 2 Trial.” Int. J. Radiat. Oncol. Biol. Phys., vol. 94, no. 1, pp. 118-125, Jan. 2016, doi: 10.1016/j.ijrobp.2015.09.011

[90] M. S. Moran et al., "Association of Radiotherapy Boost for Ductal Carcinoma in Situ with Local Control After Whole-Breas Radiotherapy.," JAMA Oncol., vol. 3, no. 8, pp. 1060-1068, Aug 2017, doi: 10.1001/jamaoncol.2016.6948

[91] E. Ippolito et al., "Hypofractionated radiotherapy with concomitant boost for breast cancer: a dose escalation study." Br. J. Radiol., vol. 92 , no. 1095, p. 20180169, Mar. 2019, doi: 10.1259/bjr.20180169.

[92] S. Park, S. Do Ahn, E. K. Choi, and S. S. Kim, "The effect of escalating the boost dose for patients with involved resection margin after breastconserving surgery.” Jpn. J. Clin. Oncol., vol. 48, no. 3, pp. 272-277, Mar. 2018, doi: 10.1093/jjco/hyy002.

[93] M. C. De Santis et al., "Comparison of two radiation techniques for the breast boost in patients undergoing neoadjuvant treatment for breas cancer.,” Br. J. Radiol., vol. 89, no. 1066, p. 20160264, Oct. 2016, doi 10.1259/bjr.20160264.

[94] P. Pinnarò et al., "Short course hypofractionated whole breast irradiation after conservative surgery: a single institution phase II study.” J. Exp. Clin. Cancer Res., vol. 36, no. 1, p. 191, Dec. 2017, doi 10.1186/s13046-017-0640-z.

[95] I. Kindts, A. Laenen, T. Depuydt, and C. Weltens, "Tumour bed boost radiotherapy for women after breast-conserving surgery." Cochrane database Syst. Rev., vol. 11, no. 11, p. CD011987, Nov. 2017, doi 10.1002/14651858.CD011987.pub2.

[96] N. Bromham, M. Schmidt-Hansen, M. Astin, E. Hasler, and M. W. Reed, "Axillary treatment for operable primary breast cancer.," 
Cochrane database Syst. Rev., vol. 1, no. 1, p. CD004561, Jan. 2017, doi: 10.1002/14651858.CD004561.pub3.

[97] E. Phillips, "MEDICAL PRELIMINARIES FOR LONDON STUDENTS.” British Medical Journal, vol. 1, no. 2686. p. 1456, Jun1912.

[98] H. A. Jones et al., "Impact of pathological characteristics on local relapse after breast-conserving therapy: a subgroup analysis of the EORTC boost versus no boost trial.” J. Clin. Oncol. Off. J. Am. Soc. Clin. Oncol., vol. 27, no. 30, pp. 4939-4947, Oct. 2009, doi: 10.1200/JCO.2008.21.5764.

[99] J. Nsaful et al., "Experiences and challenges in the management of pregnancy-associated breast cancer at the Korle Bu Teaching Hospital: a review of four cases." Ecancermedicalscience, vol. 14. p. 1140, 2020, doi: 10.3332/ecancer.2020.1140.

[100] D. J. Klionsky et al., "Guidelines for the use and interpretation of assays for monitoring autophagy (3rd edition).," Autophagy, vol. 12 no. 1, pp. 1-222, 2016, doi: 10.1080/15548627.2015.1100356.

[101] J. Sun, Z. Huang, Z. Hu, and R. Sun, "Benefits of local tumor excision and pharyngectomy on the survival of nasopharyngeal carcinoma patients: a retrospective observational study based on SEER database.,"
J. Transl. Med., vol. 15, no. 1, p. 116, May 2017, doi: 10.1186/s12967017-1204-X

[102] L.-S. Zheng et al., "SPINK6 Promotes Metastasis of Nasopharyngeal Carcinoma via Binding and Activation of Epithelial Growth Factor Receptor.," Cancer Res., vol. 77, no. 2, pp. 579-589, Jan. 2017, doi: 10.1158/0008-5472.CAN-16-1281.

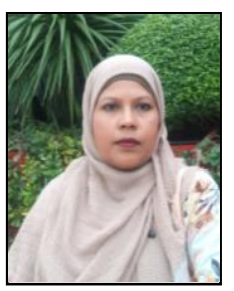

Dr Rawshan ara Khatun passed MBBS from Sher-e-Bangla Medical College,Barishal. She obtained MPhil in Radiotherapy from Rajshahi University. Now She is working as an Assistant Professor Dept of Radiation oncology at Rajshahi medical college Hospital. 